\title{
Endoscopic ultrasound-guided gallbladder drainage versus percutaneous cholecystostomy for high risk surgical patients with acute cholecystitis: a systematic review and meta-analysis
}

\author{
Authors \\ Sally Wai-Yin Luk ${ }^{1}$, Shayan Irani², Rajesh Krishnamoorthi ${ }^{2}$, James Yun Wong Lau ${ }^{3}$, Enders Kwok Wai Ng ${ }^{3}$, Anthony \\ Yuen-Bum Teoh ${ }^{3}$
}

Institutions

1 Department of Surgery, North District Hospital, Sheung Shui, Hong Kong

2 Division of Gastroenterology and Hepatology, Virginia Mason Medical Center, Seattle, Washington, United States

3 Department of Surgery, Prince of Wales Hospital, The Chinese University of Hong Kong, Sha Tin, Hong Kong

submitted 20.11.2018

accepted after revision 23.4 .2019

Bibliography

DOI https://doi.org/10.1055/a-0929-6603

Published online: 25.6.2019 | Endoscopy 2019; 51: 722-732

(c) Georg Thieme Verlag KG Stuttgart · New York ISSN 0013-726X

Corresponding author

Anthony Y. B. Teoh, FRCSEd, Department of Surgery, Prince of Wales Hospital, Shatin, New Territories, Hong Kong SAR Fax: +852-35057974

anthonyteoh@surgery.cuhk.edu.hk

$\circledast$ Supplementary material, Fig. 1s-3s

Online content viewable at:

https://doi.org/10.1055/a-0929-6603

\section{ABSTRACT}

Background Recent evidence suggests that endoscopic ultrasound-guided gallbladder drainage (EUS-GBD) is an effective and safe alternative to percutaneous drainage (PT-
GBD). We conducted a systematic review and meta-analysis to compare these two procedures in high risk surgical patients with acute cholecystitis.

Methods A comprehensive electronic literature search was conducted for all articles published up to October 2017 to identify comparative studies between EUS-GBD and PT-GBD. A meta-analysis was performed on outcomes including technical success, clinical success, post-procedure adverse events, length of hospital stay, unplanned hospital readmission, need for reintervention, recurrent cholecystitis, and disease- or treatment-related mortality for these two procedures.

Results Five comparative studies (206 patients in the EUSGBD group vs. 289 patients in the PT-GBD group), were included in the final analysis. There were no statistically significant differences in technical success (odds ratio [OR] $0.43,95 \%$ confidence interval $[\mathrm{Cl}] 0.12$ to 1.58 ; $P=0.21$; $R^{2}=0 \%$ ) and clinical success (OR $1.07,95 \% \mathrm{Cl} 0.36$ to 3.16 ; $P=0.90 ; P^{2}=44 \%$ ) between the two procedures. EUS-GBD had fewer adverse events than PT-GBD (OR 0.43, 95\%Cl 0.18 to $1.00 ; P=0.05 ; P^{2}=66 \%$ ). Moreover, patients undergoing EUS-GBD had shorter hospital stays, with pooled standard mean difference of $-2.53(95 \% \mathrm{Cl}-4.28$ to -0.78 ; $\left.P=0.005 ; I^{2}=98 \%\right)$, and required significantly fewer reinterventions (OR $0.16,95 \% \mathrm{Cl} 0.04$ to $0.042 ; P<0.001 ; P^{2}=32 \%$ ) resulting in significantly fewer unplanned readmissions (OR $0.16,95 \% \mathrm{Cl} 0.05$ to $0.53 ; P=0.003 ; P^{2}=79 \%$ ).

Conclusions EUS-GBD was associated with lower rates of post-procedure adverse events, shorter hospital stays, and fewer reinterventions and readmissions compared with PTGBD in patients with acute cholecystitis who were unfit for surgery.

\section{Introduction}

In patients with acute cholecystitis, early laparoscopic cholecystectomy is the gold standard treatment [1,2]. For patients with serious comorbidities deemed unfit for surgery, a nonoperative approach with percutaneous gallbladder drainage (PT-GBD) is a safe alternative treatment option [3,4]. Nonetheless, several challenges remain with the long term use of PT-
GBD, including tube dysfunction, pain, bile leaks, readmission, and reintervention, with adverse events ranging from $4 \%$ to $51 \%$. These not only affect patients' quality of life but could also result in higher costs of care in the long term [5-7].

With the emergence of endoscopic ultrasound-guided gallbladder drainage (EUS-GBD) since 2007 [8,9], the technique has rapidly evolved with different stents being used for drainage. The 2018 Tokyo guidelines also accepts EUS-GBD per- 
formed by experienced endoscopists in high volume centers as an alternative approach to draining the gallbladder in patients who are high risk candidates for cholecystectomy [1]. A few comparative studies with relatively small sample sizes then compared the outcomes of EUS-GBD with those of PT-GBD in patients with acute cholecystitis who were unfit for surgery. We therefore conducted a systematic review and meta-analysis to compare the effectiveness and safety of the two procedures.

\section{Methods}

\section{Identification and search strategy}

This systematic review was performed in accordance with the Cochrane Handbook for Systematic Reviews of Interventions [10]. It is reported according to the Preferred Reporting Items for Systematic Reviews and Meta-Analyses (PRISMA) [11] and Meta-analysis of Observational Studies in Epidemiology (MOOSE) guidelines [12]. A comprehensive electronic literature search was conducted for all articles published up to October 2017 using PubMed, MEDLINE, EMBASE, and Cochrane Central Register of Controlled Trials. Search terms included MeSH and non-MeSH terms relating to "endoscopic ultrasound-guided gallbladder drainage," "EUS-guided gallbladder drainage”, "percutaneous cholecystostomy", "percutaneous gallbladder drainage" in combination. An additional search was conducted using hand-searching through references and bibliographies of relevant studies. Our search was limited to articles published in the English language. Duplicated, abstract-only, and nonrelevant articles were excluded. Articles were selected for full-text review based on their title and abstract.

\section{Inclusion and exclusion criteria}

We only selected comparative cohorts, both randomized control trials (RCTs) and observational cohort studies, comparing the effectiveness and safety between EUS-GBD and PT-GBD in nonsurgical patients with acute cholecystitis. In these studies, patients were considered by a surgeon to be at too high a risk to undergo cholecystectomy. Only endoscopic ultrasoundguided transmural drainage of the gallbladder was included, thus excluding papers that used endoscopic transpapillary drainage. Studies were included only if they reported all three primary outcomes of interest: 1) clinical success, defined as resolution of clinical symptoms and/or improvement in biochemical parameters; 2) technical success, defined as the ability to access and drain the gallbladder by placement of a drainage tube or stent with immediate drainage of bile; and 3) post-procedure adverse events. Two authors independently identified original articles for review of eligibility and validity. Any disagreement between reviewers was discussed with a third reviewer for final consensus.

\section{Study selection and data extraction}

Extracted data included study design and period, patient demographics, clinical characteristics, method of drainage including mode of anesthesia, route of drainage, and type of stent used in EUS-GBD. Technical success, clinical success, adverse events, post-procedural pain score, length of hospital stay, need for reintervention, number of unplanned readmissions, recurrent cholecystitis, 30-day disease-specific mortality, and duration of follow-up were also evaluated. In the event of missing data, the corresponding authors were contacted for further details.

\section{Quality assessment}

We used the Cochrane tool to assess risk of bias for RCTs [10] and the Newcastle-Ottawa scale (NOS) for observational cohort studies [13]. The Cochrane tool assesses presence of several biases including selection, performance, detection, attrition, and reporting. NOS measures quality in three parameters including selection, comparability, and exposure/outcome with a maximum of 4,2 , and 3 points, respectively. High quality studies score over 7 , moderate quality studies score between 5 and 7 , and low quality studies score under 5 .

\section{Data synthesis}

Primary outcome measures were technical success, clinical success, and post-procedure adverse events. Technical success was defined as the ability to access and drain the gallbladder by placement of a drainage tube or stent with immediate drainage of bile. Clinical success was defined as the resolution of clinical symptoms and/or improvement in biochemical parameters. The severity of adverse events was graded according to the lexicon of endoscopic adverse events [14].

Secondary outcome measures included length of hospital stay, the need for reintervention, number of unplanned readmissions, recurrent cholecystitis, and 30-day disease-specific mortality.

\section{Statistical analysis}

Odds ratios (ORs) were calculated for categorical variables and means with standard deviation were calculated for continuous variables. Weights for individual studies were based on the model of meta-analysis used to estimate the effect size, which is represented by the size of the squares on the forest plot. Overall results were analyzed using a random effects model of meta-analysis. For assessment of heterogeneity, the $R^{2}$ statistic was used, with $R^{2}$ values $>50 \%$ representing moderate heterogeneity. Sensitivity analysis was performed in case of significant heterogeneity. Prediction interval was calculated to estimate the range of dispersion of the calculated pooled rates [15]. Publication bias was illustrated by funnel plots. Subgroup analysis was performed for studies using lumen-apposing metal stents (LAMS) in EUS-GBD group vs. PT-GBD.

All analyses were carried out using Review Manager software (RevMan Version 5.3 for Mac; The Cochrane Collaboration, The Nordic Cochrane Centre, Copenhagen, Denmark).

\section{Results}

\section{Search strategy yield and quality assessment}

The electronic literature search identified 189 studies, and 27 additional studies were identified through manual search of references and bibliographies from relevant studies. A total of 32 studies were duplicated and 82 studies were removed as ab- 
stract-only articles or were irrelevant by title. Of the $102 \mathrm{ab}$ stracts, 61 of them were excluded because of the type or design of the study. Finally, 41 full-text articles were reviewed for eligibility, of which 30 were review articles, 4 were systematic reviews of endoscopic methods of gallbladder drainage, one was a meta-analysis of the effectiveness and safety of endoscopic gallbladder drainage including both transpapillary and transmural drainage, and one was a comparative study not using EUS-GBD; all of these studies were excluded. Ultimately, five studies - one RCT [16] and four comparative cohort studies [17-20] - were included in the final meta-analysis. Results of the search strategy are shown in $>$ Fig. 1 .

Three studies [18-20] were multicenter studies and two $[16,17]$ were from a single tertiary care center. A total of 495 patients were included in the meta-analysis, 206 of whom underwent EUS-GBD and 289 underwent PT-GBD. Four studies $[16,17,19,20]$ used 2013 Tokyo guidelines for the diagnosis of acute cholecystitis [21], with typical clinical presentation (fever, right upper quadrant pain, positive Murphy sign, elevated leukocyte count) and radiological findings consistent with acute cholecystitis. A total of 376 patients (76.0\%; 146 EUSGBD and 230 PT-GBD) had calculous cholecystitis, and 82 patients (16.6\%) had acalculous cholecystitis, of whom 39 underwent EUS-GBD and 43 underwent percutaneous cholecystotomy; the remaining $7.5 \%$ were listed as other causes, including malignancy.
All patients were deemed unfit for emergency surgery owing to significant comorbidities, either American Society of Anesthesiologists grade III or above, or Charlson Comorbidity Index score $\geq 4$. EUS-GBD was performed under general anesthesia in more than half of the patients (51.5\%) whereas most PT-GBD procedures were performed under local anesthesia with or without sedation.

Four studies used EUS-GBD as the initial drainage method, whereas in one study, EUS-GBD was used only after a failed attempt at transpapillary drainage [16]. Three studies [18-20] mentioned the route of drainage in the EUS-GBD group: 76 patients were drained via the transgastric route and 70 patients via the transduodenal route. Three studies [18-20] used LAMS in the EUS-GBD group and two studies used nasobiliary drains [16] and fully covered self-expandable metal stents (FCSEMS) [17], respectively.

Two studies $[19,20]$ used the American Society for Gastrointestinal Endoscopy lexicon to grade adverse events, and three studies [16-18] defined procedure-related adverse event as early (<24 hours) and delayed ( $>1$ day after the procedure). For the follow-up protocol, the cholecystostomy tube was removed at the time of cholecystectomy in the Jang et al. study [16], whereas three studies $[17,19,20]$ had the tube removed at $6-8$ weeks, once cystic duct patency was demonstrated on cholecystogram. The time of removal was not clearly mentioned in the Tyberg et al. study [18]. One author (Teoh AY)

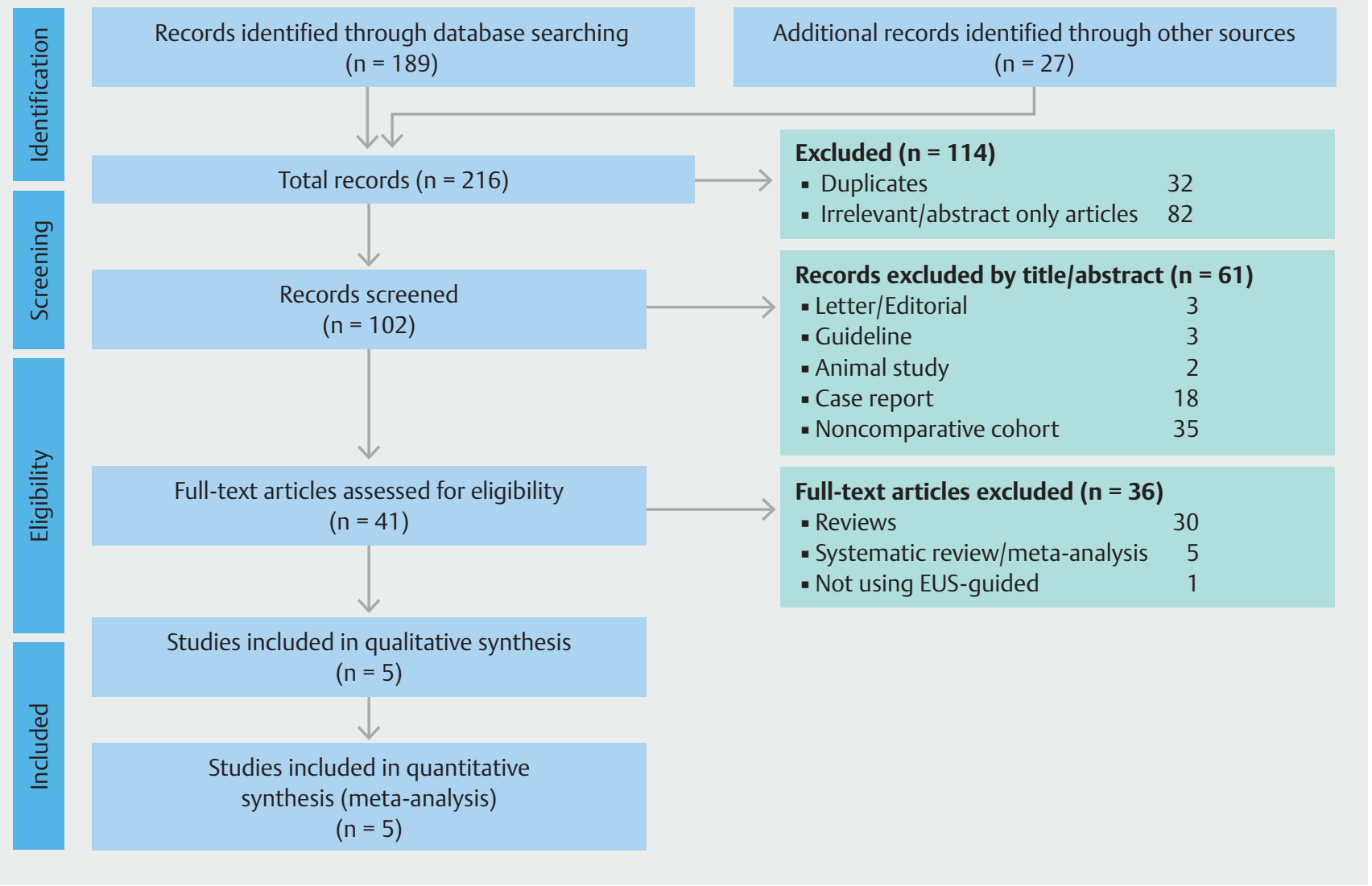

- Fig. 1 Flow diagram of the literature search according to the Preferred Reporting Items for Systematic Reviews and Meta-Analyses. 
was noted to have participated in three studies involving LAMS for EUS-GBD. It was clarified with the author that there was no overlapping of cases.

According to the Cochrane tool, the RCT by Jang et al. [16] had a low risk of selection, reporting, and attrition bias, but had a performance bias due to the lack of blinding of both patients and personnel performing the procedure. All four observational cohort studies [17-20] were of high quality based on NOS. The included studies were also reviewed for confounding bias. The authors found no significant difference in the baseline characteristics between the "intervention" and "control" arms in the individual studies and we estimate the risk of confounding bias to be low. Study characteristics, outcome measures, and quality assessment of the included studies are summarized in $>$ Table 1 and $>$ Table 2.

\section{Meta-analysis}

All included studies compared the effectiveness and safety of EUS-GBD and PT-GBD. There were no statistically significant differences in technical and clinical success of EUS-GBD and PT-GBD. The pooled ORs for technical and clinical success were $0.43(95 \% \mathrm{Cl} 0.12$ to $1.58 ; P=0.21 ; P=0 \%)(\triangleright$ Fig. 2$)$ and 1.07 ( $95 \% \mathrm{Cl} 0.36$ to $3.16 ; P=0.90 ; P^{2}=44 \%$ ) ( $\triangleright$ Fig. 3 ), respectively. The calculated prediction intervals for technical and clinical success were $0.43(95 \% \mathrm{Cl} 0.05$ to 3.56$)$ and $1.07(95 \%$ $\mathrm{Cl} 0.05$ to 24.00 ), respectively. The funnel plots are illustrated in Fig. 1 s and Fig. 2s in the online-only Supplementary material. On sensitivity analysis by removing each study sequentially, there was no change in the effect size for clinical success.

The pooled OR for overall adverse events was $0.43(95 \% \mathrm{Cl}$ 0.18 to $1.00 ; P=0.05 ; P^{2}=66 \%$ ), in favor of EUS-GBD ( $>\mathbf{F i g . 4}$ ). The calculated prediction interval for adverse events was 0.43 (95\% Cl 0.03 to 6.83). The funnel plot is illustrated in Fig. 3s.

- Table 1 Study characteristic and patient demographics.

\begin{tabular}{|c|c|c|c|c|c|c|c|c|c|c|c|}
\hline Study & Design & $\begin{array}{l}\text { Study } \\
\text { period }\end{array}$ & Center & $\begin{array}{l}\text { Etiology, } \\
\text { n }\end{array}$ & $\begin{array}{l}\text { Grou- } \\
\text { ps }\end{array}$ & $\begin{array}{l}\text { Pa- } \\
\text { tients, } \\
\text { n }\end{array}$ & $\begin{array}{l}\text { Male, } \\
\text { n }\end{array}$ & $\begin{array}{l}\text { Age, } \\
\text { mean } \\
(\mathrm{SD}) \text {, } \\
\text { years }\end{array}$ & $\begin{array}{l}\text { Comor- } \\
\text { bidity } \\
\text { index }\end{array}$ & $\begin{array}{l}\text { Type of } \\
\text { anesthe- } \\
\text { sia }\end{array}$ & Stent \\
\hline \multirow{2}{*}{$\begin{array}{l}\text { Jang } \\
\text { et al. } \\
2012 \\
{[16]}\end{array}$} & \multirow[t]{2}{*}{$\mathrm{RCT}$} & \multirow{2}{*}{$\begin{array}{l}\text { Jun } \\
2010- \\
\text { Dec } 2010\end{array}$} & \multirow{2}{*}{$\begin{array}{l}\text { Single } \\
\text { center } \\
\text { South } \\
\text { Korea }\end{array}$} & $\begin{array}{l}\text { Calcu- } \\
\text { lous } 50\end{array}$ & $\begin{array}{l}\text { EUS- } \\
\text { GBD }\end{array}$ & 30 & 17 & $62(15)$ & $\begin{array}{l}\text { ASAIII/IV: } \\
25 / 5\end{array}$ & $\begin{array}{l}\text { Midazolam } \\
30\end{array}$ & NBD \\
\hline & & & & $\begin{array}{l}\text { Acalcu- } \\
\text { lous } 9\end{array}$ & $\begin{array}{l}\text { PT- } \\
\text { GBD }\end{array}$ & 29 & 21 & $68(10)$ & $\begin{array}{l}\text { ASAIII/IV: } \\
28 / 1\end{array}$ & LA 29 & Plastic \\
\hline \multirow[t]{2}{*}{$\begin{array}{l}\text { Kedia } \\
\text { et al. } \\
2015 \\
{[17]}\end{array}$} & \multirow[t]{2}{*}{ Retro. } & \multirow[t]{2}{*}{$\begin{array}{l}\text { July } \\
2011 \text { - } \\
\text { Nov } 2013\end{array}$} & \multirow[t]{2}{*}{$\begin{array}{l}\text { Single } \\
\text { center } \\
\text { New } \\
\text { York }\end{array}$} & $\begin{array}{l}\text { Calcu- } \\
\text { lous } 45\end{array}$ & $\begin{array}{l}\text { EUS- } \\
\text { GBD }\end{array}$ & 30 & 14 & $\begin{array}{l}62.5 \\
(18.3)\end{array}$ & CCl 6.1 & GA 30 & $\begin{array}{l}\text { DP/ } \\
\text { FCSEMS } \\
+ \text { DP }\end{array}$ \\
\hline & & & & $\begin{array}{l}\text { Acalcu- } \\
\text { lous } 28\end{array}$ & $\begin{array}{l}\text { PT- } \\
\text { GBD }\end{array}$ & 43 & 23 & $\begin{array}{l}66.9 \\
(18.0)\end{array}$ & CCI 5.6 & $\begin{array}{l}\text { Sedation } \\
36\end{array}$ & Plastic \\
\hline \multirow[t]{4}{*}{$\begin{array}{l}\text { Tyberg } \\
\text { et al. } \\
2016 \\
{[18]}\end{array}$} & \multirow[t]{4}{*}{ Retro. } & \multirow[t]{4}{*}{$\begin{array}{l}\text { Jan } \\
2010- \\
\text { Dec 2015 }\end{array}$} & \multirow[t]{4}{*}{$\begin{array}{l}\text { Multi- } \\
\text { center } \\
7\end{array}$} & $\begin{array}{l}\text { Calcu- } \\
\text { lous } 102\end{array}$ & $\begin{array}{l}\text { EUS- } \\
\text { GBD }\end{array}$ & 42 & 24 & $\begin{array}{l}74.0 \\
(14.9)\end{array}$ & $\mathrm{CCl} 4.76$ & $\begin{array}{l}\text { GA } 36 \\
\text { Sedation } \\
6\end{array}$ & $\begin{array}{l}\text { LAMS/ } \\
\text { FCSEMS/ } \\
\text { plastic }\end{array}$ \\
\hline & & & & $\begin{array}{l}\text { Acalcu- } \\
\text { lous } 16\end{array}$ & $\begin{array}{l}\text { PT- } \\
\text { GBD }\end{array}$ & 113 & 63 & $\begin{array}{l}74.37 \\
(14.33)\end{array}$ & $\mathrm{CCl} 4.83$ & $\begin{array}{l}\text { GA } 22 \\
\text { Sedation } \\
26\end{array}$ & Plastic \\
\hline & & & & $\begin{array}{l}\text { Malig- } \\
\text { nancy } 34\end{array}$ & & & & & & LA 76 & \\
\hline & & & & Other 3 & & & & & & & \\
\hline \multirow{2}{*}{$\begin{array}{l}\text { Irani } \\
\text { et al. } \\
2017 \\
\text { [19] }\end{array}$} & \multirow[t]{2}{*}{ Retro. } & \multirow{2}{*}{$\begin{array}{l}\text { July } \\
2013- \\
\text { Dec } 2015\end{array}$} & \multirow{2}{*}{$\begin{array}{l}\text { Multi- } \\
\text { center } \\
7\end{array}$} & $\begin{array}{l}\text { Calcu- } \\
\text { lous } 61\end{array}$ & $\begin{array}{l}\text { EUS- } \\
\text { GBD }\end{array}$ & 45 & 29 & $\begin{array}{l}65(25- \\
87)^{*}\end{array}$ & $\begin{array}{l}\text { ASAIV/V: } \\
26 / 3\end{array}$ & GA 40 & LAMS \\
\hline & & & & $\begin{array}{l}\text { Acalcu- } \\
\text { lous } 29\end{array}$ & $\begin{array}{l}\text { PT- } \\
\text { GDB }\end{array}$ & 45 & 27 & $\begin{array}{l}75(34- \\
94)^{*}\end{array}$ & $\begin{array}{l}\text { ASAIV/V: } \\
31 / 5\end{array}$ & GA 5 & Plastic \\
\hline \multirow{2}{*}{$\begin{array}{l}\text { Teoh } \\
\text { et al. } \\
2017 \\
{[20]}\end{array}$} & \multirow[t]{2}{*}{ Retro. } & \multirow{2}{*}{$\begin{array}{l}\text { Nov } \\
2011- \\
\text { Aug } \\
2014\end{array}$} & \multirow{2}{*}{$\begin{array}{l}\text { Multi- } \\
\text { center } \\
2\end{array}$} & \multirow[t]{2}{*}{$\begin{array}{l}\text { Calcu- } \\
\text { lous } 118\end{array}$} & $\begin{array}{l}\text { EUS- } \\
\text { GBD }\end{array}$ & 59 & 30 & $\begin{array}{l}82.7 \\
(7.9)\end{array}$ & CCI 5.6 & $\begin{array}{l}\text { Sedation/ } \\
\text { MAC } 59\end{array}$ & LAMS \\
\hline & & & & & $\begin{array}{l}\text { PT- } \\
\text { GBD }\end{array}$ & 59 & 30 & $\begin{array}{l}81.2 \\
(10.4)\end{array}$ & CCI 5.8 & LA 59 & Plastic \\
\hline
\end{tabular}


- Table 2 Outcome measures and quality assessment of included studies.

\begin{tabular}{|c|c|c|c|c|c|c|c|c|c|c|c|c|c|}
\hline Study & $\begin{array}{l}\text { Grou- } \\
\text { ps }\end{array}$ & $\begin{array}{l}\text { Tech- } \\
\text { nical } \\
\text { suc- } \\
\text { cess, } \\
\text { n }\end{array}$ & $\begin{array}{l}\text { Clini- } \\
\text { cal } \\
\text { suc- } \\
\text { cess, } \\
\text { n }\end{array}$ & $\begin{array}{l}\text { AEs, } \\
n\end{array}$ & $\begin{array}{l}\text { Pain, } \\
\text { n }\end{array}$ & $\begin{array}{l}\text { Length } \\
\text { of stay, } \\
\text { mean } \\
\text { (SD), } \\
\text { days }\end{array}$ & $\begin{array}{l}\text { Re-in- } \\
\text { terven- } \\
\text { tion, } n\end{array}$ & $\begin{array}{l}\text { Re-ad- } \\
\text { mis- } \\
\text { sion, } n\end{array}$ & $\begin{array}{l}\text { Recur- } \\
\text { rent } \\
\text { chole- } \\
\text { cystitis, } \\
\text { n }\end{array}$ & $\begin{array}{l}\text { Mor- } \\
\text { tality, } \\
\text { n }\end{array}$ & $\begin{array}{l}\text { Follow- } \\
\text { up, } \\
\text { mean } \\
\text { (SD), } \\
\text { days }\end{array}$ & \multicolumn{2}{|c|}{ Quality } \\
\hline \multirow{2}{*}{$\begin{array}{l}\text { Jang } \\
\text { et al. } \\
2012 \\
{[16]}\end{array}$} & $\begin{array}{l}\text { EUS- } \\
\text { GBD }\end{array}$ & 29 & 29 & 2 & $\begin{array}{l}\text { Medi- } \\
\text { an } 1\end{array}$ & NA & NA & NA & NA & NA & \multirow[t]{2}{*}{$\begin{array}{l}90 \text { or } \\
\text { surgery }\end{array}$} & \multirow{2}{*}{\multicolumn{2}{|c|}{$\begin{array}{l}\text { High risk of } \\
\text { performance } \\
\text { bias }\end{array}$}} \\
\hline & $\begin{array}{l}\text { PT- } \\
\text { GBD }\end{array}$ & 28 & 27 & 1 & $\begin{array}{l}\text { Medi- } \\
\text { an } 5\end{array}$ & NA & NA & NA & NA & NA & & & \\
\hline \multirow{2}{*}{$\begin{array}{l}\text { Kedia } \\
\text { et al. } \\
2015 \\
{[17]}\end{array}$} & $\begin{array}{l}\text { EUS- } \\
\text { GBD }\end{array}$ & 30 & 26 & 4 & 2.1 & $\begin{array}{l}7.6 \\
(2.5)\end{array}$ & 4 & 4 & NA & NA & $\begin{array}{l}267 \\
(219)\end{array}$ & NOS & 7 \\
\hline & $\begin{array}{l}\text { PT- } \\
\text { GBD }\end{array}$ & 42 & 42 & 17 & 3.8 & $\begin{array}{l}16.3 \\
(5.5)\end{array}$ & 23 & 17 & NA & NA & $\begin{array}{l}282 \\
(252)\end{array}$ & $4 / 1 / 2$ & \\
\hline \multirow{2}{*}{$\begin{array}{l}\text { Tyberg } \\
\text { et al. } \\
2016 \\
{[18]}\end{array}$} & $\begin{array}{l}\text { EUS- } \\
\text { GBD }\end{array}$ & 40 & 40 & 9 & NA & $\begin{array}{l}8.3 \\
(2.4)\end{array}$ & 4 & 6 & 3 & 0 & $\begin{array}{l}\text { Median } \\
133\end{array}$ & NOS & 7 \\
\hline & $\begin{array}{l}\text { PT- } \\
\text { GBD }\end{array}$ & 112 & 97 & 24 & NA & $\begin{array}{l}17.5 \\
(4.3)\end{array}$ & 28 & 27 & 9 & 4 & $\begin{array}{l}\text { Median } \\
231\end{array}$ & $4 / 1 / 2$ & \\
\hline \multirow{2}{*}{$\begin{array}{l}\text { Irani } \\
\text { et al. } \\
2017 \\
{[19]}\end{array}$} & $\begin{array}{l}\text { EUS- } \\
\text { GBD }\end{array}$ & 44 & 43 & 8 & 2.5 & $\begin{array}{l}4.5 \\
(0.8)\end{array}$ & 11 & 6 & 3 & 1 & $\begin{array}{l}\text { Median } \\
215\end{array}$ & NOS & 8 \\
\hline & $\begin{array}{l}\text { PT- } \\
\text { GDB }\end{array}$ & 45 & 41 & 14 & 6.5 & $\begin{array}{l}16.1 \\
(2.7)\end{array}$ & 112 & 22 & 4 & 3 & $\begin{array}{l}\text { Median } \\
265\end{array}$ & $4 / 2 / 2$ & \\
\hline \multirow{2}{*}{$\begin{array}{l}\text { Teoh } \\
\text { et al. } \\
2017 \\
{[20]}\end{array}$} & $\begin{array}{l}\text { EUS- } \\
\text { GBD }\end{array}$ & 57 & 53 & 19 & NA & $\begin{array}{l}9.5 \\
(6.1)\end{array}$ & 1 & 4 & 0 & 5 & $\begin{array}{l}450.7 \\
(343.1)\end{array}$ & NOS & 8 \\
\hline & $\begin{array}{l}\text { PT- } \\
\text { GBD }\end{array}$ & 59 & 56 & 44 & NA & $\begin{array}{l}11.2 \\
(6.4)\end{array}$ & 16 & 42 & 4 & 1 & $\begin{array}{l}834.1 \\
(416.6)\end{array}$ & $4 / 2 / 2$ & \\
\hline
\end{tabular}

AE, adverse event; SD, standard deviation; EUS-GBD, endoscopic ultrasound-guided gallbladder drainage; PT-GBD, percutaneous gallbladder drainage; NA, not assessed; NOS, Newcastle-Ottawa scale.

Moderate heterogeneity was found among included studies; thus, sensitivity analysis was performed to evaluate the presence of skewness related to the different study protocols. The study conducted by Jang et al. [16] evaluated the early postoperative outcomes and included only adverse events occurring within 1 week of the procedure. The effect size was more significant when this study was excluded. The remaining four studies included both early complications and disease-related adverse events during the follow-up period. The most common adverse events associated with PT-GBD were tube-related adverse events, ranging from $58.8 \%$ to $75 \%$ in the included cohorts. The difference appeared to be independent of the difference in duration of follow-up between the groups. There was no statistically significant difference in the overall mean duration of follow-up between the EUS-GBD group and the PT-GBD group ( 231.1 vs. 340.4 days; $P=0.43$ ). Among the studies, significant differences in duration of follow-up were observed in two studies only: Teoh et al. adjusted the confounding effects of duration of follow-up by performing a Cox's proportional hazards regression for predictors of overall adverse events, whereas no statistically significant difference in adverse events were observed in the study reported by Tyberg et al.

Among the four observational studies [17-20] with a total of 436 patients (176 EUS-GBD and 260 PT-GBD), there were also no statistically significant differences in technical and clinical success of EUS-GBD and PT-GBD; the pooled ORs for technical and clinical success were $0.34(95 \% \mathrm{Cl} 0.08$ to $1.47 ; P=$ $\left.0.15 ; P^{2}=0 \%\right)$ and $0.95(95 \% \mathrm{Cl} 0.26$ to $3.39 ; P=0.93 ; P=56 \%)$, respectively. The pooled OR for overall adverse events was 0.37 ( $95 \% \mathrm{Cl} 0.16$ to $0.89 ; P=0.03 ; P^{2}=70 \%$ ); thus, patients who underwent EUS-GBD experienced significantly fewer adverse events.

The four observational studies also compared length of hospital stay, reintervention rates and unplanned readmissions as secondary outcomes. Patients who underwent EUS-GBD had significantly shorter hospital stays, with a pooled standard mean difference of $-2.53\left(95 \% \mathrm{Cl}-4.28\right.$ to $-0.78 ; P=0.005 ; P^{2}=$ $98 \%$ ) ( Fig.5a). The calculated prediction interval for length of hospital stay was $-2.53(95 \% \mathrm{Cl}-11.01$ to 5.95$)$. Fewer reinterventions were required after EUS-GBD, with a pooled OR of 0.16 ( $95 \% \mathrm{Cl} 0.06$ to $0.042 ; P<0.001 ; P^{2}=32 \%$ ) ( $>$ Fig. 5b). Similarly, patients who underwent EUS-GBD had significantly fewer unplanned readmissions, with a pooled OR of $0.16(95 \% \mathrm{Cl} 0.05$ to $0.53 ; P=0.003 ; P=79 \%$ ) ( $\triangleright$ Fig. $5 \mathbf{c}$ ). The calculated prediction intervals for reintervention and unplanned readmission were $0.16(95 \% \mathrm{Cl} 0.01$ to 3.18$)$ and $0.16(95 \% \mathrm{Cl} 0.00$ to 33.54), respectively. The number of follow-up procedures performed was also significantly lower in the EUS-GBD group vs. 


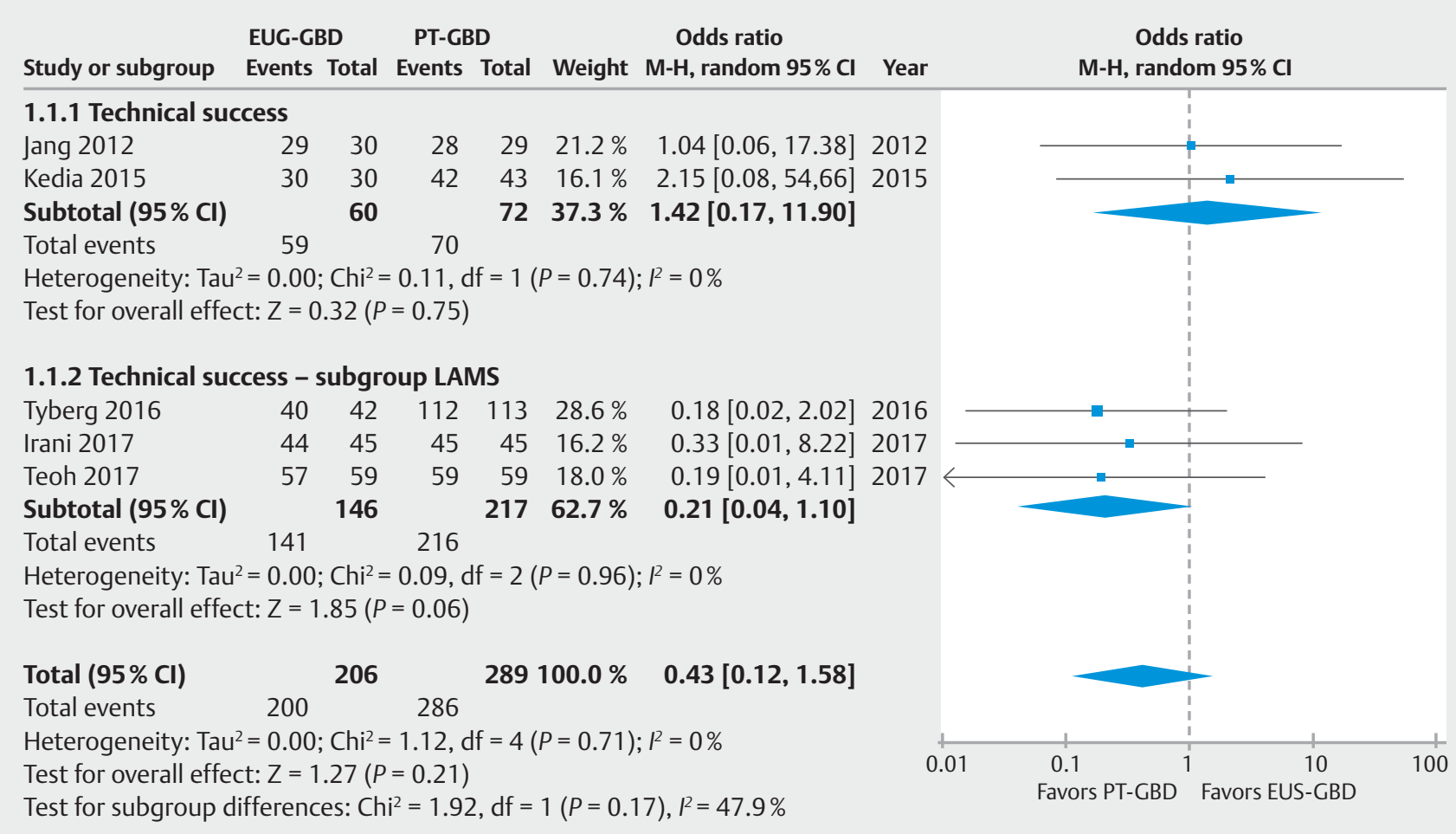

- Fig. 2 Comparison of technical success between endoscopic ultrasound-guided gallbladder drainage (EUS-GBD) and percutaneous gallbladder drainage (PT-GBD). M-H, Mantel-Haenszel; Cl, confidence interval; LAMS, lumen-apposing metal stent.

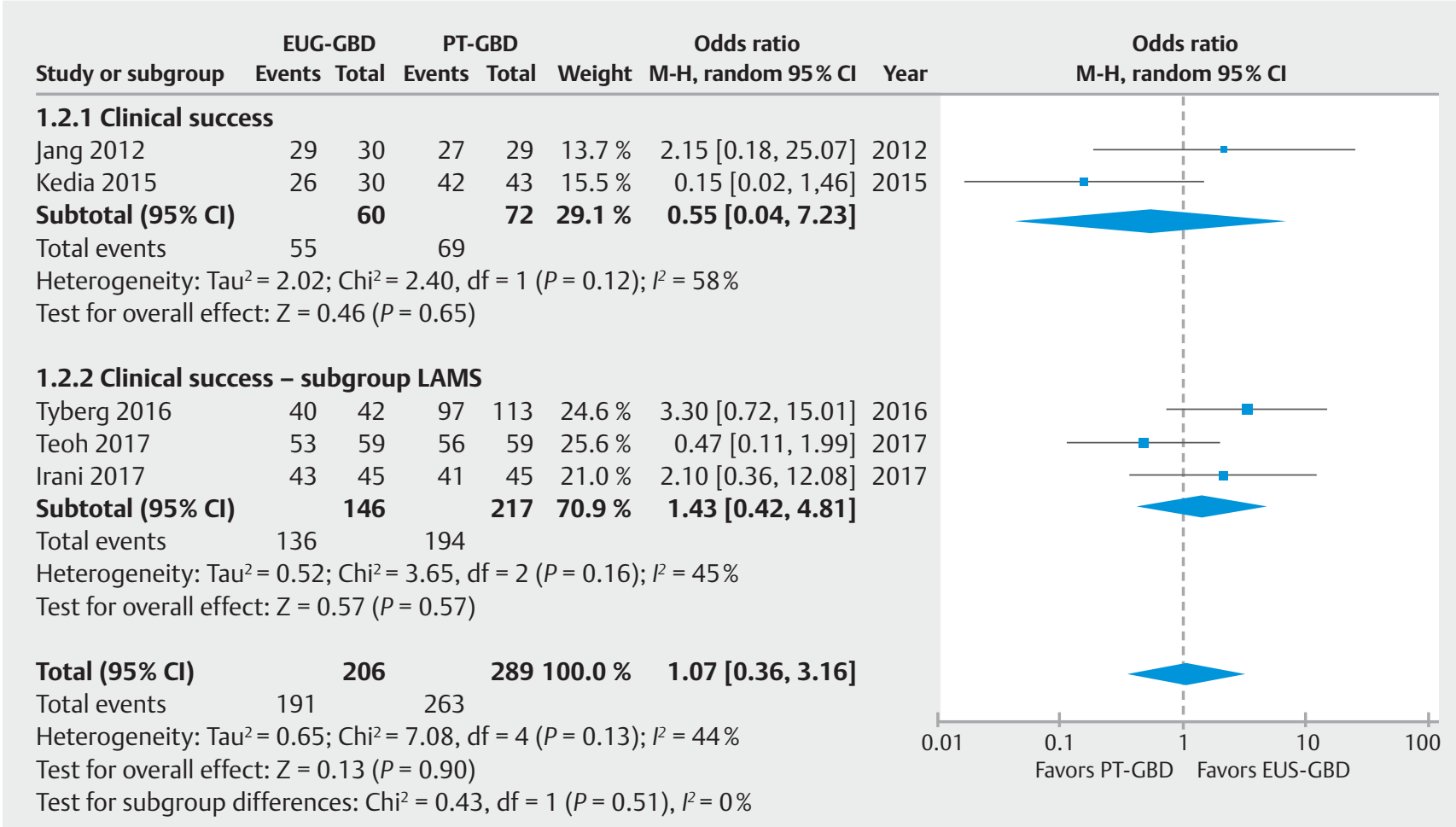

- Fig. 3 Comparison of clinical success between endoscopic ultrasound-guided gallbladder drainage (EUS-GBD) and percutaneous gallbladder drainage (PT-GBD). M-H, Mantel-Haenszel; Cl, confidence interval; LAMS, lumen-apposing metal stent. 


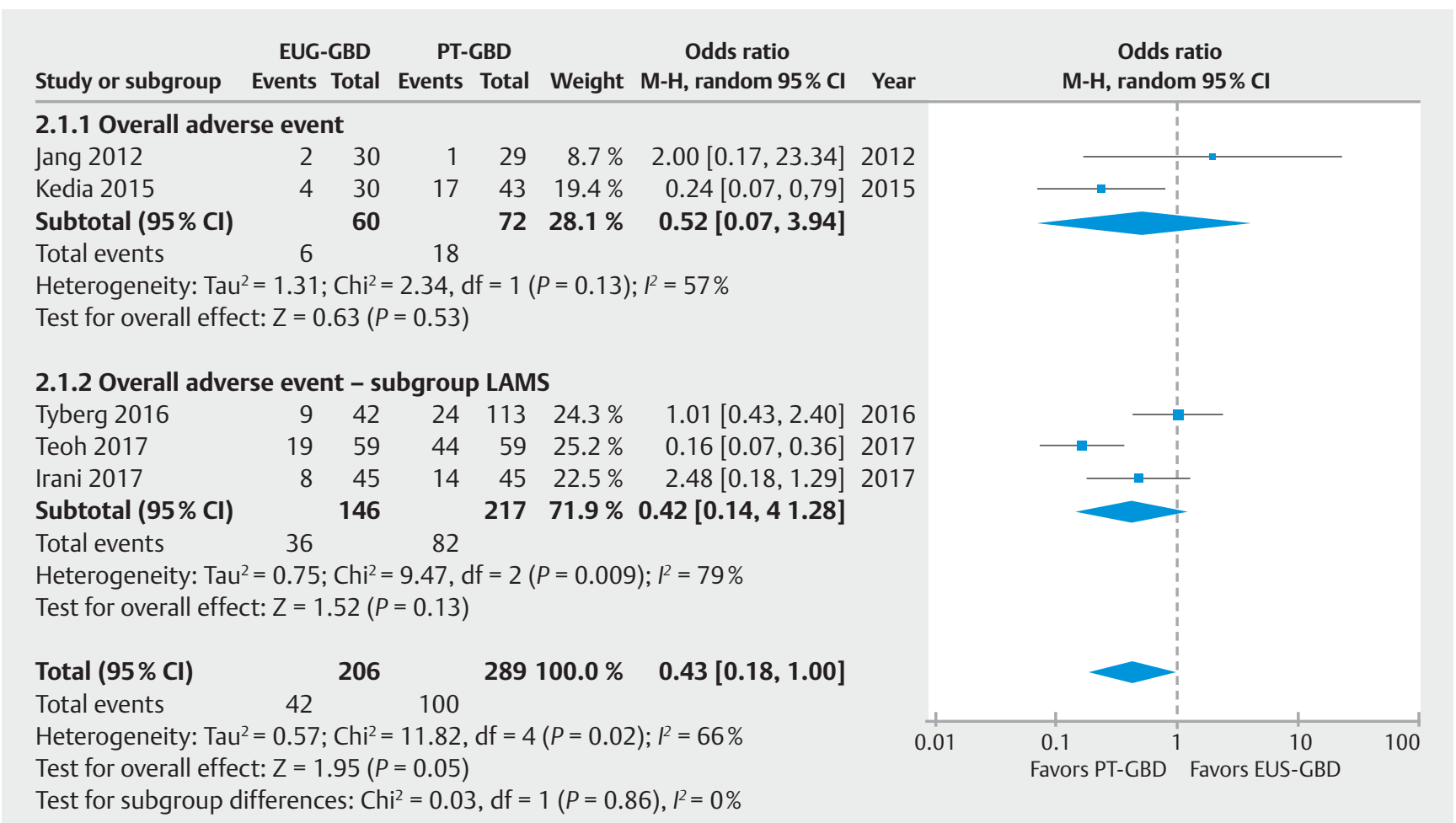

- Fig. 4 Comparison of overall adverse events between endoscopic ultrasound-guided gallbladder drainage (EUS-GBD) and percutaneous gallbladder drainage (PT-GBD). M-H, Mantel-Haenszel; Cl, confidence interval; LAMS, lumen-apposing metal stent.

the PT-GBD group (20/220 procedures vs. 179/465; $P<0.001)$. Problems related to the cholecystostomy tube were responsible for most of the readmissions in the PT-GBD group, as mentioned in the two studies $[19,20]$. Sensitivity analysis performed for length of hospital stay and unplanned readmissions did not show any change in effect size.

Three studies $[16,17,19]$ compared the post-procedure highest pain score within 1 day of intervention between the two procedures. The use of a visual analog scale was mentioned in two studies. As different parameters were used (one assessed the median post-procedure pain score and two used mean pain score), no meta-analysis was performed for this outcome measure. Overall, all three studies consistently reported that patients experienced significantly less pain after EUS-GBD than after PT-GBD.

Three studies $[17,19,20]$ recruited genuine nonsurgical candidates for cholecystectomy as an inclusion criterion. As a result, 81 patients (16.4\%) underwent cholecystectomy (25 EUS-GBD and 56 PT-GBD). According to the study by Jang et al. [16], there was no statistically significant difference in conversion rate to open surgery between EUS-GBD (9\%) and PTGBD (12\%; $P=0.99)$. The ease of surgery after either endoscopic or percutaneous procedures was not mentioned.

\section{Subgroup analysis for EUS-GBD using LAMS}

Three studies [18-20] using LAMS, with a total 363 patients (146 EUS-GBD LAMS and 217 PT-GBD) were included in the subgroup analysis. Two studies $[19,20]$ used LAMS exclusively in EUS-GBD drainage, and one study [18] used both plastic and metal stents (including FCSEMS and LAMS). One study placed double-pigtail plastic stents in addition to FCSEMS [17]. There were no statistically significant differences in technical and clinical success between EUS-GBD LAMS and PT-GBD. The pooled ORs for the technical success and clinical success were $0.21\left(95 \% \mathrm{Cl} 0.04\right.$ to $\left.1.10 ; P=0.06 ; P^{2}=0 \%\right)(\triangleright$ Fig. 2$)$ and 1.43 (95\% Cl 0.42 to $4.81 ; P=0.57 ; P^{2}=45 \%$ ) ( Fig. 3 ), respectively. In addition, no statistically significant difference in adverse events was observed, with a pooled OR of $0.42(95 \% \mathrm{Cl} 0.14$ to $1.28 ; P=0.13 ; P^{2}=79 \%$ ) ( $\triangleright$ Fig. 4 ).

The outcomes according to the route of EUS drainage (either transgastric or transduodenal) were compared in two studies $[18,20]$ and there were no statistically significant differences in terms of technical success and adverse event rate.

All three studies in the subgroup analysis compared the length of hospital stay, reintervention rates, and unplanned readmissions between the two procedures. Hospital stays were shorter for EUS-GBD LAMS than for PT-GBD, with a pooled standard mean difference of $-2.76(95 \% \mathrm{Cl}-5.20$ to $-0.31 ; P=$ $0.03 ; R^{2}=99 \%$ ) ( Fig.6a). Patients who underwent EUS-GBD had fewer unplanned readmissions and reinterventions, with pooled ORs of $0.14\left(95 \% \mathrm{Cl} 0.03\right.$ to $\left.0.70 ; P=0.02 ; P^{2}=86 \%\right)$ ( $>$ Fig. 6 b) and $0.15\left(95 \% \mathrm{Cl} 0.02\right.$ to $0.98 ; P=0.05 ; P^{2}=63 \%$ ) ( $>$ Fig. 6c), respectively.

Furthermore, recurrent cholecystitis and disease-related mortality were also compared in all three studies as secondary outcome measures. The observed percentage of recurrent cho- 


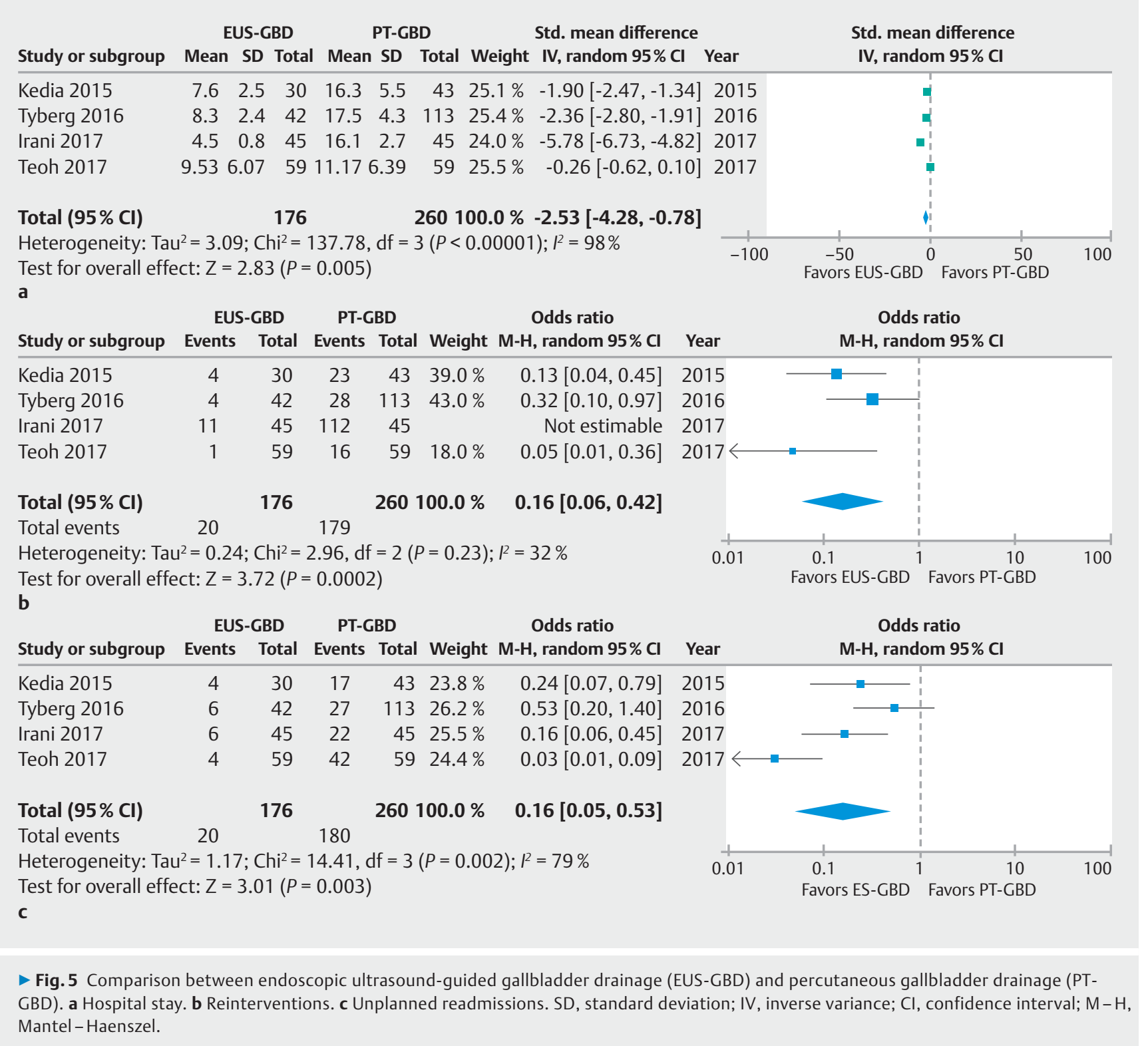

lecystitis was $4.1 \%$ after EUS-GBD LAMS drainage and $7.83 \%$ after PT-GBD. No statistical difference in recurrent cholecystitis was observed between the two groups, with a pooled OR of 0.65 (95\% 0.25 to $1.72 ; P=0.39 ; P^{2}=0 \%$ ) ( $>$ Fig. 6 d). The disease-related mortality was also not different between the two groups, at 4.1\% (6 patients) for EUS-GBD LAMS and 3.7\% (8 patients) for PT-GBD, with a pooled OR of $0.89(95 \% \mathrm{Cl} 0.12$ to $6.46 ; P=0.91 ; P^{2}=49 \%$ ) ( $>$ Fig. $6 \mathbf{e}$ ).

\section{Discussion}

The gold standard treatment for acute cholecystitis is laparoscopic cholecystectomy [1]. In patients who are high risk candidates for cholecystectomy, gallbladder drainage with PT-GBD in the acute setting is highly efficacious at relieving the obstruction [3-5]. Alternatively, drainage of the gallbladder can be achieved endoscopically using either transpapillary stenting via endoscopic retrograde cholangiopancreatography (ERCP) or transmural drainage by EUS-GBD. However, the transpapillary approach may be difficult due to a small or tortuous cystic duct, or obstruction by gallstones, tumor or stents. The route also carries a risk of ERCP-related pancreatitis [22]. Thus, EUSGBD has gained popularity over the endoscopic transpapillary approach [23, 24].

This meta-analysis affirms that EUS-GBD had comparable effectiveness to PT-GBD for high risk surgical patients with acute cholecystitis, in terms of technical and clinical success rates. Our analysis suggests that patients with PT-GBD experienced more adverse events than those treated by EUS-GBD. The majority of adverse events after PT-GBD were catheter-related, including dislodgment, migration, obstruction, and peri-tubal leakage. With EUS-GBD, the adverse events were procedureor stent-related events including bleeding, perforation, and bile leaks. However, we encountered a moderate heterogeneity 


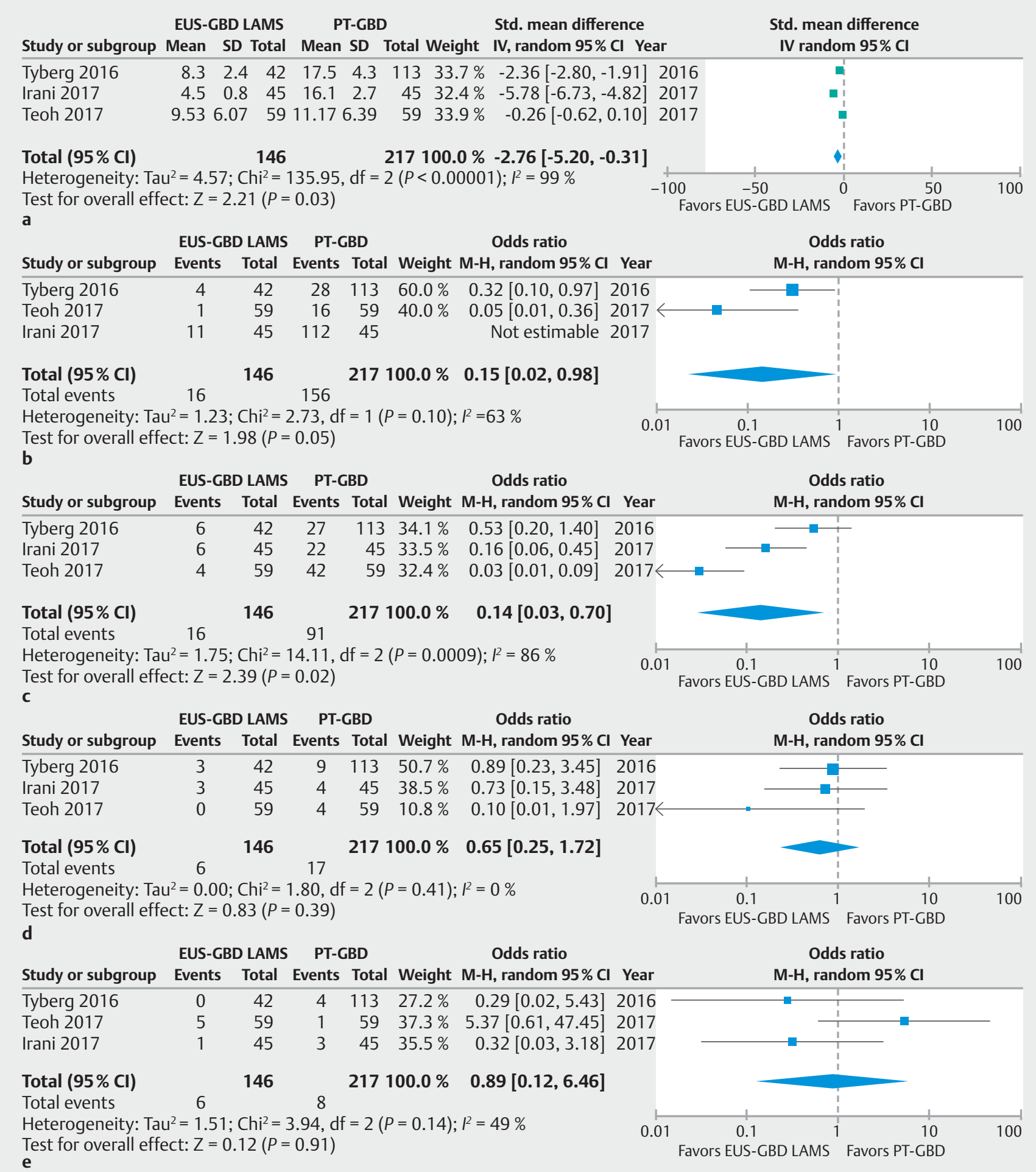

- Fig. 6 Comparison between endoscopic ultrasound-guided gallbladder drainage (EUS-GBD) using lumen-apposing metal stents and percutaneous gallbladder drainage (PT-GBD). a Hospital stay. b Reinterventions. c Unplanned readmissions. d Recurrent cholecystitis. e Mortality. SD, standard deviation; IV, inverse variance; $\mathrm{Cl}$, confidence interval; $\mathrm{M}-\mathrm{H}$, Mantel-Haenszel.

in this estimation. A number of patients in the PT-GBD group were from historical cohorts with longer follow-up (i.e. lead time bias). However, significant differences in duration of follow-up were observed in only two studies. Teoh et al. [20] ad- justed the confounding effects of duration of follow-up by performing a Cox's proportional hazards regression for predictors of overall adverse events, whereas no statistically significant difference in adverse events were observed in the study report- 
ed by Tyberg et al. [18]. Thus, the likelihood of lead time bias producing the observed differences in adverse events is low.

Apart from the tube cholecystogram to check the patency of the cystic duct and common bile duct, there is no consensus on the management of PT-GBD after placement. Some advocate tube removal at 6-8 weeks after placement, once cystic duct patency is demonstrated on the tube cholecystogram [6, 7, 25]. This could minimize tube-related complications and patient discomfort but does nothing to reduce the risk of recurrent cholecystitis. Thus, different practices in the management of PT-GBD could partly explain the discrepancy in the observed unplanned remission rates among these studies.

A few published systematic reviews and meta-analyses have addressed the comparability of EUS-GBD vs. PT-GBD. The first systematic review was reported as a subgroup analysis with three published studies [26]. At least half of the drainage procedures performed in the studies were via the transpapillary route (i.e. non-EUS drainage) and only six patients underwent transmural drainage using metal stents. In another meta-analysis, Anderloni et al. [23] reported that different types of stents, including plastic, SEMS, and LAMS, used for EUS-GBD in acute cholecystitis have comparable effectiveness to PT-GBD. Our current meta-analysis went the extra step with regard to reporting the secondary outcomes of interest (length of hospital stay, readmission rate, and reintervention rate) that were missing in the original papers, by contacting the corresponding authors. Jang et al. [16] did not assess those outcomes owing to the study protocol, with drainage procedure as an interim measure before elective cholecystectomy. Our meta-analysis of the other four studies favored EUS-GBD, with significantly shorter hospital stays, and fewer unplanned readmissions and reinterventions. Subgroup analysis with LAMS also showed similar results. However, this conclusion has to be interpreted with caution because of the substantial heterogeneity in the studies. The variation in hospital stay for the two procedures may be related to the difference in post-drainage protocols, discharging criteria, social support, and cultural belief among various countries. Nevertheless, patients undergoing EUS-GBD were discharged earlier on average (i. e. mean 7.5 days vs. 15.3 days in the PT-GBD group).

Undoubtedly, there are several limitations to the current meta-analysis. The number of included studies was small for meta-analysis. Furthermore, the presence of publication bias is difficult to address with fewer than 10 studies. Besides, most included studies were retrospective in nature, which poses a certain risk of selection bias and lead time bias. The heterogeneity in post-drainage protocol among different centers also weakens the reliability of assessing the secondary outcome measures. In addition, estimation of confounding bias was limited by the baseline characteristic or confounding factors that were considered in individual studies. Further evaluation from an ongoing international RCT (NCT02212717) with a standardized protocol comparing EUS-GBD with PT-GBD is expected to shed more light on these limitations.

In conclusion, this meta-analysis demonstrated that EUSGBD is associated with lower rates of post-procedure adverse events, shorter hospital stays, and fewer reinterventions and readmissions compared with PT-GBD in patients with acute cholecystitis who are unfit for surgery.

\section{Acknowledgment}

An abstract of this study was presented at Digestive Disease Week, 2 - 5 June 2018, Washington D.C.

\section{Competing interests}

Prof. Teoh is a consultant for Boston Scientific, Cook, Taewoong, and Microtech Medical Corporations.

\section{References}

[1] Mori Y, Itoi T, Baron TH et al. Tokyo Guidelines 2018: management strategies for gallbladder drainage in patients with acute cholecystitis (with videos). J Hepatobiliary Pancreat Sci 2018; 25: 87-95

[2] Wu XD, Tian X, Liu MM et al. Meta-analysis comparing early versus delayed laparoscopic cholecystectomy for acute cholecystitis. $\mathrm{Br}$ ] Surg 2015; 102: $1302-1313$

[3] Glenn F. Cholecystostomy in the high risk patient with biliary tract disease. Ann Surg 1977; 185: 185-191

[4] Melin MM, Sarr MG, Bender CE et al. Percutaneous cholecystostomy: a valuable technique in high-risk patients with presumed acute cholecystitis. Br J Surg 1995; 82: 1274-1277

[5] Winbladh A, Gullstrand P, Svanvik J et al. Systematic review of cholecystostomy as a treatment option in acute cholecystitis. HPB (Oxford) 2009; 11: 183-193

[6] McKay A, Abulfaraj M, Lipschitz ]. Short- and long-term outcomes following percutaneous cholecystostomy for acute cholecystitis in high-risk patients. Surg Endosc 2012; 26: 1343 - 1351

[7] Alvino DML, Fong ZV, McCarthy C] et al. Long-term outcomes following percutaneous cholecystostomy tube placement for treatment of acute calculous cholecystitis. J Gastrointest Surg 2017; 21: 761-769

[8] Baron TH, Topazian MD. Endoscopic transduodenal drainage of the gallbladder: implications for endoluminal treatment of gallbladder disease. Gastrointest Endosc 2007; 65: $735-737$

[9] Lee SS, Park DH, Hwang CY et al. EUS-guided transmural cholecystostomy as rescue management for acute cholecystitis in elderly or high-risk patients: a prospective feasibility study. Gastrointest Endosc 2007; 66: $1008-1012$

[10] Higgins J, Green S (eds.) Cochrane handbook for systematic reviews of interventions version 5.1. 0. The Cochrane collaboration; 2011: Available from: http://handbook.cochrane.org

[11] Liberati A, Altman DG, Tetzlaff J et al. The PRISMA statement for reporting systematic reviews and meta-analyses of studies that evaluate healthcare interventions: explanation and elaboration. $\mathrm{Br}$ Med J 2009; 339: b2700

[12] Stroup DF, Berlin JA, Morton SC et al. Meta-analysis of observational studies in epidemiology: a proposal for reporting. Meta-analysis Of Observational Studies in Epidemiology (MOOSE) group. JAMA 2000; 283: $2008-2012$

[13] Wells GA, Shea B, O'Connell D et al. The Newcastle-Ottawa Scale (NOS) for assessing the quality of nonrandomized studies in metaanalyses. Available from: http://www.ohri.ca/programs/clinical_epidemiology/oxford.htm

[14] Cotton PB, Eisen GM, Aabakken L et al. A lexicon for endoscopic adverse events: report of an ASGE workshop. Gastrointest Endosc 2010; 71: $446-454$ 
[15] Riley RD, Higgins JP, Deeks JJ. Interpretation of random effects metaanalyses. Br Med J 2011; 342: d549

[16] Jang JW, Lee SS, Song TJ et al. Endoscopic ultrasound-guided transmural and percutaneous transhepatic gallbladder drainage are comparable for acute cholecystitis. Gastroenterology 2012; 142: $805-$ 811

[17] Kedia P, Sharaiha RZ, Kumta NA et al. Endoscopic gallbladder drainage compared with percutaneous drainage. Gastrointest Endosc 2015; 82: $1031-1036$

[18] Tyberg A, Saumoy M, Sequeiros EV et al. EUS-guided versus percutaneous gallbladder drainage: Isn't it time to convert? J Clin Gastroenterol 2016: doi:10.1097/MCG.0000000000000786

[19] Irani S, Ngamruengphong S, Teoh A et al. Similar efficacies of endoscopic ultrasound gallbladder drainage with a lumen-apposing metal stent versus percutaneous transhepatic gallbladder drainage for acute cholecystitis. Clin Gastroenterol Hepatol 2017; 15: 738-745

[20] Teoh AY, Serna C, Penas I et al. Endoscopic ultrasound-guided gallbladder drainage reduces adverse events compared with percutaneous cholecystostomy in patients who are unfit for cholecystectomy. Endoscopy 2017; 49: 130-138
[21] Yokoe M, Takada T, Strasberg SM et al. TG13 diagnostic criteria and severity grading of acute cholecystitis (with videos). J Hepatobiliary Pancreat Sci 2013; 20: 35-46

[22] Itoi T, Coelho-Prabhu N, Baron TH. Endoscopic gallbladder drainage for management of acute cholecystitis. Gastrointest Endosc 2010; 71 : $1038-1045$

[23] Anderloni A, Buda A, Vieceli F et al. Endoscopic ultrasound-guided transmural stenting for gallbladder drainage in high-risk patients with acute cholecystitis: a systematic review and pooled analysis. Surg Endosc 2016; 30: $5200-5208$

[24] Patil R, Ona MA, Papafragkakis C et al. Endoscopic ultrasound-guided placement of the lumen-apposing self-expandable metallic stent for gallbladder drainage: a promising technique. Ann Gastroenterol 2016; 29: $162-167$

[25] Davis CA, Landercasper J, Gundersen LH et al. Effective use of percutaneous cholecystostomy in high-risk surgical patients: techniques, tube management, and results. Arch Surg 1999; 134: 727 - 731

[26] Khan MA, Atiq O, Kubiliun $\mathrm{N}$ et al. Efficacy and safety of endoscopic gallbladder drainage in acute cholecystitis: Is it better than percutaneous gallbladder drainage? Gastrointest Endosc 2017; 85: 76-87 